\title{
Transoral per punctum excision of an impacted parotid duct stone of unfavorable direction: a case report
}

\author{
Mohammad Waheed El-Anwar * (D), Karima Gaid, Mohamed Hassan Nasr and Noura Abd El Aziz Ahmed
}

\begin{abstract}
Background: In the literature, the reported parotid duct stones that did not respond to the conservative measures are few. The present work reported and described the diagnosis and treatment of a case of impacted parotid duct stone that was surgically removed through minimally invasive transoral per punctum approach.

Case presentation: On examination of a 27-year-old male with left intermittent parotid swelling and pain for 1 year, a stone was palpated in the left buccal mucosa region near the orifice of the parotid duct. Ultrasonography (US) showed left Stensen's duct distal stone. Under general anesthesia and oral intubation, the stone measuring about $1 \mathrm{~cm}$ in length was felt transversely located (directed at a right angle with the orifice of the duct). A small mucosal incision was done at the upper lateral part of the punctum; pus came out, and then the stone bulged from the orifice and was pushed outside. Recovery was event-less; postoperative paracetamol was sufficient to relieve pain, and the patient was discharged a few hours after the surgery.

Conclusion: The transoral per punctum excision of an impacted parotid duct stone appears to be a reliable minimally invasive effective and safe procedure. The unfavorable direction of the parotid duct stone might be a cause of failure of the conservative treatment for this stone.
\end{abstract}

Keywords: Parotid gland, Parotid duct, Stone

\section{Background}

Sialoliths (salivary stones) are the most popular disease of the salivary glands in middle-aged patients [1]. Most salivary stones $(>80 \%)$ occur in the submandibular gland or duct, while $6-15 \%$ occur in the parotid gland and approximately $2 \%$ in the sublingual and minor salivary glands [1]. The tortuous and long pathway of Wharton's duct contributes to stasis leading to more stone formation in the submandibular salivary system than in the parotid $[2,3]$.

Most salivary stones are small (commonly $<1 \mathrm{~cm}$ ); however, megalith (giant calculi) had been reported. The salivary stones are composed of mineralized debris that collect within the duct lumen including calcium

* Correspondence: mwenteg1973@gmail.com

Department of Otorhinolaryngology, Head-Neck Surgery, University of Zagazig, Zagazig, Egypt

\section{Springer Open}

phosphate, carbon and trace amount of magnesium, potassium, and ammonium. Salivary stones grow up by deposit at an estimated annual rate of 1 to $1.5 \mathrm{~mm}$ [4].

Sialoliths represent the common reason of salivary gland infections: acute or chronic. The resulting salivary stasis from formation of calculi permits bacterial ascent into the gland increasing the risk of bacterial colonization and gland infection [5].

Parotid duct calculi were documented, and almost always they spontaneously descend through the duct orifice. In the literature, few reported parotid duct stones did not respond to the conservative measures.

Thus, this study described in detail the diagnosis and treatment of an impacted parotid duct stone due to its unfavorable direction, at a right angle with the orifice of the duct preventing stone exit. 


\section{Case presentation}

A 27-year-old male came to the otorhinolaryngology department with recurrent left check pain and parotid gland swelling that gradually increased during mastication and spontaneously lessened of 1 year duration. A stony hard mass was palpated in the region of the left buccal mucosa, supposing a possible stone obstruction of the parotid duct. On milking the parotid gland, the left salivary flow was less free than the right side.

Ultrasonography (US) showed a homogeneous echo pattern with mild dilatation of the left parotid duct with seen distal stone about $4 \mathrm{~mm}$ (Fig. 1). The preoperative laboratory tests were within normal.

After informed written consent was obtained, under general anesthesia and oral intubation, the Boyle-Davis mouth gag was inserted exposing the duct orifice. A stone $(1 \mathrm{~cm}$ in length) was felt and bulging near the ductal orifice (Fig. 2a). The stone was transversely located (directed at a right angle with the orifice of the duct). A small mucosal incision was done at the upper lateral part of the punctum; pus came out through the duct orifice. Then, the stone bulged from the orifice (Fig. 2b) and was pushed outside while changing its direction to be parallel to the duct course so it was easily pushed outside the duct. The stone was elongated in a shape of about $1 \mathrm{~cm}$ in length (Fig. 2c). After milking of the gland, hemostasis was insured, and no significant bleeding was detected without the need to use any cautery. No wound closure was done. Recovery was eventless, oral paracetamol was sufficient to relive postoperative pain, and the patient was discharged a few hours after the surgery. Throughout the 1 year follow-up, there was no recurrence or further complaint.

\section{Discussion}

Salivary gland duct obstruction by stone leads to classical symptoms of pain and swelling of the involved gland during eating with largest salivary production and flow that is pushed against a fixed obstruction. Usually, subsequent gradual decrease of the swelling happens, but when the salivary flow is re-stimulated, the manifestations recur. Thus, the patients usually have attacks of swelling and discomfort or may have more lasting symptoms because of aggregation of the saliva within the duct.

The currently reported case complained of the classical relapsing manifestations of parotid swelling and pain.

Occasionally, stone can be palpated as hard small pebble. Less commonly, they are visible as granular masses at orifice of the gland duct [6]. In the current case, the stone was palpated near the orifice but was not seen. But intense obstruction of the duct leads to intraoral tenderness with parotid gland swelling and absence of salivary flow from the ductal orifice on gland milking.

Diagnostic imaging to denote the clinically suggested salivary calculi include US, conventional radiography, high-resolution CT, and sialography. Here, we depended on the US that confirmed the presence of the stone. US identifies the calculus as echogenic structures with glandular inflammatory alterations of the parotid gland. Thus, there was no need for other forms of radiology.

US could detect the radiopaque or radiolucent stone, so we preferred it in the parotid stone that tends to be more radiolucent than submandibular stone.

Thus, US represents an excellent first level diagnostic tool with a $99 \%$ accuracy, and it could detect the ductal and highly mineralized stones even with a small diameter down to $1.5 \mathrm{~mm}$ [7]. US can detect up to $90 \%$ of salivary duct stones and is able to visualize radiolucent stones [8]. Some stones cannot be picked up on the Xray films but can be easily seen by the US because 20 $40 \%$ of the stones are not radio-opaque [9].

Despite most sialoliths being composed of calcium elements, they are not associated with systemic calcium abnormalities [6], so the serum calcium level is within normal limits in the currently reported case.

The decision about which technique to utilize depends on the stone location and size, the accessible equipment, and surgeon experiences [6]. Stone less than $2 \mathrm{~mm}$ in diameter can be typically managed conservatively.

A conservative approach includes good hydration, proper analgesia, glandular massage in trial to milk the stone out, local warmness, and sialagogues to enhance
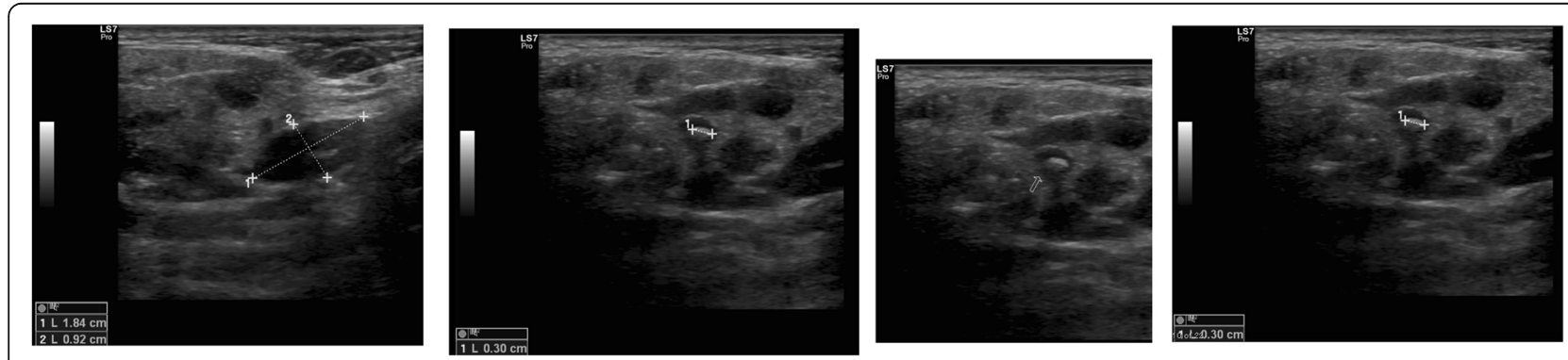

Fig. 1 Ultrasonography showed homogeneous echo pattern with mild dilatation of the left Stensen's duct 

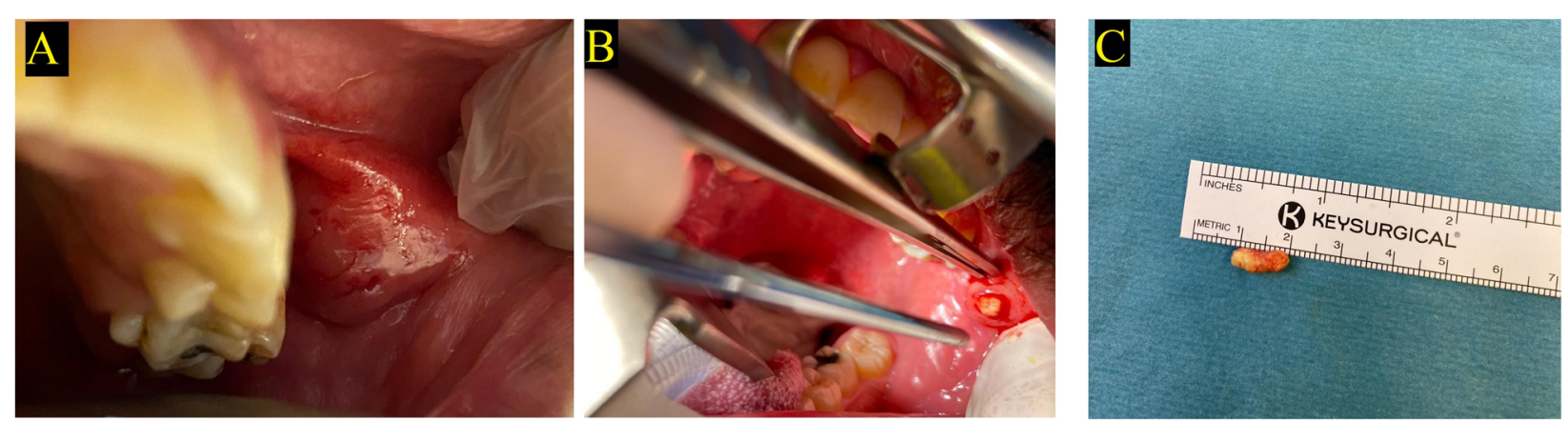

Fig. 2 a A stone was felt and seen bulging near the orifice of the parotid duct. b A small mucosal incision was done at the upper lateral part of the ductal orifice, and the stone bulged from the orifice. c Removed stone

ductal secretions. In most cases, the stone is extruded with pain relief except when an associated infection exists. Therefore, antibiotics acting on oral flora are advisable for gland super infection $[1,6]$.

Severe and resistant obstruction usually requires surgery, particularly when the blockage is adjacent to the gland. Lithotripsy, sialoendoscopy, fluoroscopy-guided wire basket extraction, and surgical removal are options after failure of the expectant management [6].

In the currently reported patient, the stone was about $1 \mathrm{~cm}$ with unfavorable direction that make it impacted and could not be squeezed or extruded out. Therefore, the conservative measures failed to extrude the stone and treat the condition. So, minimal invasive transoral

Table 1 The reported cases of transoral surgically removed parotid duct stones in the literature in comparison to the current reported case

\begin{tabular}{|c|c|c|c|c|c|c|c|}
\hline Study & Age & Sex & Clinical & Side & Duration & Radiology & Surgery \\
\hline $\begin{array}{l}\text { Sharma } \\
\text { et al. [1] }\end{array}$ & $\begin{array}{l}26 \\
\text { years }\end{array}$ & Female & $\begin{array}{l}\text { Recurrent cheek } \\
\text { swelling }\end{array}$ & Right & 3 years & $\begin{array}{l}\text { Parotid sialogram revealed duct } \\
\text { obstruction } \\
\text { CT showed radiopaque calculus }\end{array}$ & $\begin{array}{l}\text { Under general anesthesia using } \\
\text { Dormia basket, duct incised } \\
\text { intraorally, over the metal sheath } \\
\text { of the basket; remove stone } 4 \times 2 \\
\mathrm{~mm}\end{array}$ \\
\hline
\end{tabular}

$\begin{array}{llll}\begin{array}{l}\text { Moghe et al. } \begin{array}{l}25 \\ \text { [6] }\end{array} \\ \text { years }\end{array} & \text { Male } & \begin{array}{l}\text { Intermittent pain and } \\ \text { swelling, stony hard } \\ \text { mass palpated in the } \\ \text { region of the right } \\ \text { buccal mucosa }\end{array} \\ \begin{array}{llll}\text { Hathiramani } \\ \text { et al. [8] }\end{array} & \text { years } & \text { Male } & \begin{array}{l}\text { Pain, redness, and } \\ \text { swelling in the parotid } \\ \text { region } \\ \text { Fever, induration, and } \\ \text { tenderness in the } \\ \text { region of gland } \\ \text { Palpable stone in distal } \\ \text { part of duct } \\ \text { No discharge }\end{array}\end{array}$

$\begin{array}{lll}\text { Hathiramani } & 3.5 & \text { male } \\ \text { et al. [8] } & \text { years }\end{array}$

External discharging fistula with bouts of
Right 1 year

US-radiopaque substance in the region of the duct X-ray

Right 12 days 2-3 mm hyperechogenic focus pain and swelling calculus felt in the parotid duct Cervical lymph nodes palpable and nontender.

$\begin{array}{lllll}\begin{array}{l}\text { Erdem et al. } \\ \text { [10] }\end{array} & \text { Male } & \begin{array}{l}\text { Painless swelling on the } \\ \text { cheek }\end{array} & \text { Right } 1 \text { year } \\ \text { Our case } & \begin{array}{l}27 \\ \text { years }\end{array} & \text { Male } & \begin{array}{l}\text { Swelling and pain } \\ \text { Stone felt }\end{array} & \text { Left } 1 \text { year }\end{array}$

Left 3 weeks Dilated left parotid duct with thick walls communicating with the discharging sinus on the skin. A 3$\mathrm{mm}$ calculus noted in the distal end of the duct

CT-radiopaque oval about $11.19 \times$ $7.19 \mathrm{~mm}$

US-left stone in the distal duct with dilatation

Local anesthesia, stone 5-6 mm visible at the orifice with another 2 $\mathrm{mm}$ stone-stent placed

Closure

with silk

Few pus at the stenotic opening that the cannulated and duct laid open over venflon and flushed with saline

Calculus flushed out widened duct opening sutured to mucosa with 6/0 absorbable suture.

Duct was cannulated with lacrimal probe. Purulent discharge present, duct laid open but the stone could not be flushed out as the stone shifted proximally. Intraoperative US was used to identify the stone and duct was laid open to deliver the stone. Duct sutured to mucosa with $5 / 0$ absorbable sutures

Local anesthesia-transoral duct incision

General anesthesia, transoral per punctilum, small incision, and pus come first 
per punctum excision of the stone was successfully performed without negative sequels on the patients.

In the literature, few impacted parotid duct stones that were surgically removed were reported, and they were summarized in Table 1. It was noticed that all reported stones, including our case, are radiopaque and stony hard and were reported in males. This data may indicate that these characters of the parotid duct stone could be less likely to respond to conservative measures. In addition, in the current case, the unfavorable stone direction and its large size may be other contributing factors that indicate early surgical interference before the development of negative sequels such as parotid fistula and abscess.

Similar to the present case, all the reported cases had no associated medical commonalities except the case reported by Erdem et al. that represents the oldest reported case ( 52 years) and had type 2 diabetes mellitus, hypertension, and Parkinson's disease and on antiplatelet agents.

Moghe et al. [6] removed a 6-mm right parotid duct stone that was transorally removed using local anesthesia with large incision that indicates wound closure and to leave a stent.

In the current case, a small incision was used without wound closure because changing the stone direction helped to push it out. This could be performed safely and reliably while the patient is under general anesthesia without the need for stent.

In the present case, the minimally invasive transoral per punctum technique has proven to be reliable in terms of adequate exposure and stone accessibility and removal with minimal bleeding. We did not need to use extra devices as Dormia basket that adds more cost and could be unavailable. So, it is recommended to be early used in parotid duct stone of unfavorable position and required to be investigated on a series of patients.

\section{Conclusion}

The transoral per punctum excision of an impacted parotid duct stone appears to be a reliable minimally invasive effective and safe procedure. The unfavorable direction of the parotid duct stone might be a failure cause of the conservative treatment of the parotid duct stone.

\section{Abbreviations}

US: Ultrasonography

\section{Acknowledgements}

The authors thank the study participant for patience and support. information; followed up the patient; interpretation and analysis of the collected data; assisted in writing methods and revising the written manuscript; prepared the figures; and approved the submitted version. MHN: reviewed the written manuscript, assisted in preparing the figures, revised the manuscript critically for important intellectual content; and approved the submitted version. NAA: did the radiological evaluation of the patient; reviewed the written manuscript; assisted in preparing the figures; revised the manuscript critically for important intellectual content; and approved the submitted version. All authors have read and approved the manuscript.

Funding

The authors declare no financial support or interest to this study.

\section{Availability of data and materials}

The datasets used and/or analyzed during the current study are available from the corresponding author on reasonable request.

\section{Declarations}

\section{Ethics approval and consent to participate}

Informed written consent was signed by all subjects to share in the study after explanation of its purposes. No need of IRB approval as it is a reporting of a case (not applicable).

\section{Consent for publication}

The patient included in this research gave written informed consent to publish the data contained within this study. No patient that was less than

16 years old was included in this study.

\section{Competing interests}

The authors declare that they have no competing interests.

Received: 2 January 2021 Accepted: 21 April 2021

Published online: 07 May 2021

\section{References}

1. Sharma RK, Al-Khalifaa S, Paulose KO et al (1994) Parotid duct stone_removal by a dormia basket. J Laryngol Otol 108(8):699-701. https:// doi.org/10.1017/S0022215100127884

2. Wiliams MF (1999) Sialolithiasis. Otolaryngol Clin NA 32(5):819-834. https:// doi.org/10.1016/S0030-6665(05)70175-4

3. Boffano P, Gallesio C (2010) Surgical treatment of a giant sialolith of the Wharton duct. J Craniofac Surg 21(1):134-135. https://doi.org/10.1097/SCS. 0b013e3181c46bc4

4. Siddiqui SJ (2002) Sialolithiasis an unusually large submandibular salivary stone. Br Dent J 193(2):89-91. https://doi.org/10.1038/sj.bdj.4801491

5. Rabinov JD (2000) Imaging of salivary gland pathology. Radiol Clin North Am 38(5):1047-1057. https://doi.org/10.1016/S0033-8389(05)70220-7

6. Moghe S, Pillai A, Thomas S, et al. Parotid sialolithiasis. BMJ Case Rep. Published online: 14 December 2012 doi:https://doi.org/10.1136/bcr-2012007480

7. Maresh A, Kacker KA (2011) Sialoendoscopy in the diagnosis and management of obstructive sialadenitis. Laryngoscope 121(3):495-500. https://doi.org/10.1002/lary.21378

8. Hathiramani et al (2017) Parotid duct calculi: a report of two cases. J Pediatr Neonatal Care 7(4):00293

9. Gritzmann (2003) Sialolithiasis: radiological diagnosis and treatment. Eur Radiol 13(5):964-975. https://doi.org/10.1007/s00330-002-1586-9

10. Erdem S (2018) An unusual parotid sialolith diagnosis and treatment: a case report. J Dent Res Rep 1(1):1-4

\section{Publisher's Note}

Springer Nature remains neutral with regard to jurisdictional claims in published maps and institutional affiliations. 